\title{
Stable expressions with the color adjective orange in the Russian language of the 2oth century
}

\author{
E. N. Laguzova ${ }^{1}$, E. N. Martynova ${ }^{1}$
}

1Yaroslavl State Pedagogical University named after K. D. Ushinsky, 108/1 Respublikanskaya str., Yaroslavl 150000, Russian Federation

DOI: $10.18255 / 2412-6519-2021-4-440-447$

Research Article

Full text in Russian

The article presents a structural and semantic analysis of stable expressions of the 20th century with the adjective orange, many of which are based on metaphorical and associative-symbolic use of their constituent components. Among the ways of the author's transformation of such lexical units, the authors note the addition and replacement of significant parts of speech with other forms of the same word or synonyms, as well as a change in the location of the components of the expression in relation to each other, which not only does not destroy the idiom, but, on the contrary, intensifies its meaning. The evolution of the original meaning of expressions with the color adjective orange is shown, which is due to the change (expansion) of the circle of nouns combined with the adjective, the implication of evaluation, the formation of new synonymous links with metaphor. Particular attention is paid to stable expressions with political significance, the largest number of which began to appear since 2013 in connection with political events taking place in Ukraine, where orange was chosen for the symbols of the Ukrainian opposition. The development of negative connotations in the expression orange revolution is explained by the corresponding semantic potential of the adjective orange itself, for which semes with negative connotations are productive in speech. The expansion of the compatibility of the adjective orange in modern Russian has led to the emergence of new meanings for the adjectival. Using examples extracted from the newspaper subcorpus of the National Corpus of the Russian Language, representing a collection of texts of printed newspapers and electronic agencies of the 2000s, it is shown that the use of stable expressions with the color adjective orange reflects the tendency characteristic of the development of the modern Russian language to expressivize the written text in connection with the formation of an evaluative statement capable of conveying the attitude of a journalist to social, cultural, political events. At the same time, the expressed social axiological assessment performs various functions in the text: from attracting attention and overcoming the standard to manipulating the consciousness of the mass reader.

Keywords: stable expressions, adjective orange, figurative meaning, metonymic transfer, metaphor, author's transformation of stable expressions

INFORMATION ABOUT THE AUTHORS

$$
\begin{array}{c|l}
\text { Laguzova, Evgeniya N. } & \begin{array}{l}
\text { E-mail: laguzova.e@mail.ru } \\
\text { Doc. Sc. (Philology), Professor }
\end{array} \\
\text { Martynova, Elena N. } & \begin{array}{l}
\text { E-mail: martlen2009@yandex.ru } \\
\text { Cand. Sc. (Pedagogy), Associate Professor }
\end{array}
\end{array}
$$

For citation: Laguzova E. N., Martynova E. N. Stable expressions with the color adjective orange in the Russian language of the 20 th century // Social'nye i gumanitarnye znanija. 2021. Vol. 7, No 4. P. 440-447. (in Russ.)

(C) Laguzova E. N., Martynova E. N., 2021

This is an open access article under the CC BY license (https://creativecommons.org/licenses/by/4.0/) 


\title{
Устойчивые выражения с цветовым прилагательным оранжевый в русском языке XXI века
}

\author{
Е. Н. Лагузова ${ }^{1}$, Е. Н. Мартынова ${ }^{1}$
}

1Ярославский государственный педагогический университет им. К. Д. Ушинского, ул. Республиканская, 108/1, Ярославль, 150000, Российская Федерация

DOI: $10.18255 / 2412-6519-2021-4-440-447$

удк 81'373

Научная статья

Полный текст на русском языке

В статье представлен структурно-семантический анализ устойчивых выражений XXI века с прилагательным оранжевый, многие из которых основаны на метафорическом и ассоциативно-символическом использовании входящих в их состав компонентов. Среди способов авторской трансформации подобного рода лексических единиц авторы отмечают дополнение и замену знаменательных частей речи другими формами того же слова или синонимами, а также изменение расположения компонентов выражения по отношению друг к другу, что не только не разрушает идиому, а, напротив, интенсифицирует ее смысл. Показано эволюционирование исходного значения выражений с цветовым прилагательным оранжевый, которое обусловлено изменением (расширением) круга сочетающихся с прилагательным имён существительных, имплицированием оценки, образованием новых синонимических связей с метафорой. Особое внимание уделено устойчивым выражениям с политическим значением, наибольшее количество которых стало появляться с 2013 года в связи с политическими событиями, происходившими на Украине, где оранжевый цвет был выбран для символики украинской оппозиции. Развитие негативных коннотаций у выражения оранжевая революция объясняется соответствующим семантическим потенциалом самого прилагательного оранжевый, для которого семы с негативными коннотациями являются продуктивными в речи. Расширение сочетаемости прилагательного оранжевый в современном русском языке привело к появлению у адъектива новых значений. На примерах, извлечённых из газетного подкорпуса Национального корпуса русского языка, представляющего собрание текстов печатных газет и электронных агентств 2000-х гг., показано, что в употреблении устойчивых выражений с цветовым прилагательным оранжевый отражается характерная для развития современного русского языка тенденция к экспрессивизации письменного текста в связи с формированием оценочного высказывания, способного передать отношение журналиста к социальным, культурным, политическим событиям. При этом выражаемая социальная аксиологическая оценка выполняет в тексте различные функции: от привлечения внимания и преодоления стандарта до манипулирования сознанием массового читателя.

Ключевые слова: устойчивые выражения, прилагательное оранжевый, переносное значение, метонимический перенос, метафора, авторская трансформация устойчивых выражений

\section{ИНФОРМАЦИЯ ОБ АВТОРАХ} Лагузова, Евгения Николаевна
(автор для корреспонденции)

Мартынова, Елена Николаевна
Email: laguzova.e@mail.ru

Доктор филологических наук, профессор, заведующий кафедрой русского языка

E-mail: martlen2009@yandex.ru

Кандидат педагогических наук, доцент кафедры теории

и методики преподавания филологических дисциплин

Для цитирования: Лагузова Е. Н., Мартынова Е. Н. Устойчивые выражения с цветовым прилагательным оранжевый в русском языке XXI века // Социальные и гуманитарные знания. 2021. Том 7, № 4. С. 440 -447.

(C) Лагузова Е. Н., Мартынова Е. Н., 2021

Статья открытого доступа под лицензией СС BY (https://creativecommons.org/licenses/by/4.0/) 


\section{Введение}

Изменения, произошедшие в 90-е годы XX в. во всех сферах нашей жизни, привели к активному образованию в начале XXI века новых слов и выражений, среди которых особый интерес представляют устойчивые выражения, включающие в свой состав цветовые прилагательные. Это связано с кумулированием в них традиционных национальных смыслов и способностью цвета влиять на физическое и психоэмоциональное состояние человека.

Некоторые устойчивые выражения с цветовыми прилагательными в своём составе достаточно частотны, однако не отражены в современных словарях. Между тем они содержат в себе социальную аксиологическую оценку и выполняют ряд специфических функций: от привлечения внимания и преодоления стереотипов до манипулирования сознанием массового читателя. Именно этим объясняется довольно пристальное внимание к данным языковым единицам исследователей Е.А. Анохиной, И. В. Бариновой, Н. Ю. Бородулиной, В. М. Бурунского, Е. А. Власовой, Ю. В. Зольниковой, А. Н. Клевцова, М. В. Сандаковой, Н. С. Редькиной, М. Б. Талапиной, Чжан Цзе и др. [1; 2 ; $3 ; 4 ; 5 ; 6 ; 7 ; 8 ; 9 ; 10 ; 11]$. Однако в работах названных авторов рассматриваются отдельные аспекты исследуемых языковых единиц в контексте сопоставительного анализа разных языков без выявления способов переноса значений, а также способов и функций авторской трансформации подобного рода лексических единиц.

Для более детального структурно-семантического анализа нами были выбраны устойчивые выражения XXI века с прилагательным оранжевый. Именно в это время наблюдается его интенсивное использование при образовании устойчивых выражений разных типов.

Оранжевый, как и любой другой цвет, имеет противоположные символические значения: с одной стороны, это цвет теплоты и блаженства, означающий святость и здоровье, символизирующий энергию, радость, смелость; а с другой стороны, это цвет раскалённого жара, пекла, накала; сдвиг в сторону красноты прибавляет ему агрессии. Можно выделить и третье символическое значение - это сигнальный цвет, предупреждающий об опасности, требующий осторожности.

Свои наблюдения мы строили на материале фразеологизмов, извлечённых из газетного подкорпуса Национального корпуса русского языка, представляющего собрание текстов печатных газет и электронных агентств 2000-х гг.

\section{1. Устойчивые выражения с политическим значением}

Наибольшее количество устойчивых выражений с прилагательным оранжевый стало появляться с 2013 года в связи с политическими событиями, происходившими на Украине. Оранжевый цвет был использован как символом украинской оппозиции, инициировавшей революционный подъём 2004 года. Название «оранжевая революция» появилось из-за оранжевого цвета знамени Виктора Ющенко, ленточек и шарфов его сторонников. Этот цвет способствовал созданию символической ассоциации (близкой к метонимическому переносу) с языками пламени, пожаром-таким образом организаторы революции хотели добиться накала, напряжённости, драматизма.

Исходным сочетанием, на основе которого продолжают возникать переносные значения, является сочетание оранжевая революция [7, с. 147]: «Оранжевая революция привела к тому, что быть украинцем в мире стало модно, почётно и престижно», - сказал Ющенко ... Ющенко выглядел счастливым и предстал перед журналистами в чёрном костюме, белой рубашке и в оранжевом галстуке 1 . Устойчивое

\footnotetext{
${ }^{1}$ Украина не спит: сторонники Ющенко празднуют победу, штаб Януковича ждёт итогов // РИА Новости, 2004.12.27.
} 
сочетание оранжевая революция после тех украинских событий стало широко употребляться и обозначать протестное движение, смену верхушки власти в какой-либо стране.

Основное значение выражения «оранжевая революция» в ряде случаев приобретает дополнительную позитивную или негативную коннотацию в зависимости от того, какова позиция автора. Более того, мы можем наблюдать своего рода «эволюцию» исходного значения выражения в связи с изменением отношения в обществе к описываемым событиям: «Оранжевая революция» была высшей точкой национального вдохновения ; «Оранжевая революция» и прочие идеалы?2; «Оранжевая революция» отмерила начало самого тяжёлого и позорного периода истории бывшей Украинской ССРЗ; «Оранжевая революция» была лишь имитацией раскола Украины «Оранжевая революция» похожа на буйное застолье и даже лозунги - «За свободу», «За вхождение в Европу» - напоминают тосты ${ }^{5}$; «Оранжевая революция» - это уже анекдот» 6 , что «оранжевая революция» - это технология американских спецслужб7 ${ }^{7}$ Исследователи связывают развитие негативных коннотаций у выражения оранжевая революция с семантическим потенциалом прилагательного оранжевый, для которого негативные коннотации являются продуктивными в речи [10, с. 93].

Расширение сочетаемости прилагательного оранжевый в современном русском языке привело к появлению у адъектива новых значений [7, с. 147]:

1.'Оранжевый' (о сторонниках В. Ющенко) - 'такой, который поддерживает В. Ющенко на выборах' [субстантив] (о человеке/ совокупности людей)' [12, с. 9]: «Оранжевая команда» обвиняла предыдущее правительство Януковича в "развале бюджетной политики»8. В данной группе можем отметить следующие устойчивые выражения: оранжевая элита, оранжевый электорат, оранжевая Украина, оранжевые массы, оранжевый лагерь, оранжевые политики, оранжевая принцесса (Юлия Тимошенко), оранжевая власть, оранжевые депутаты, оранжевый звездопад, оранжевая коалиция9.

2. 'Оранжевый' - 'такой, который обозначает место и время проведения оранжевой революции' [12, с. 10] (оранжевые времена, оранжевая пора): «В пылу баталий появляется Владимир Литвин, тот самый, который был спикером в «оранжевую» пору и смог удержать тогда ситуацию от бойни»10.

3. 'Оранжевый'- 'такой, который связан с идеями В. Ющенко' [12, с. 9] («оранжевые идеи», «оранжевое настроение», «оранжевые волнения»): Любопытно, что Украина вошла в оба списка. Но если в рейтинге друзей она стоит только на 7-м месте, то в списке врагов возглавляет вторую пятерку - каждый четвертый опрошенный воспринимает «оранжевые настроения» нашей соседки как явно антироссийские 11.

\footnotetext{
${ }^{1}$ Дайджест российской прессы - 27 марта // РИА Новости, 2006.03.27.

${ }^{2}$ Янина Соколовская, Максим Юсин, Киев. Украина выбирала или выбрала? // Известия, 2010.01.18.

${ }^{3}$ Виталий Иванов, директор Института политики и государственного права. Грустная годовщина // Известия, 2009.11.23.

${ }^{4}$ Софья Кораблева. Украину ждёт революция // Новый регион 2, 2008.10.15.

${ }^{5}$ Дмитрий Быков. Кризис как среда // Известия, 2006.07.19.

${ }^{6}$ Итоговый выпуск (вечерний) - 22.11.05 18:40 - Екатеринбург // Новый регион 2, 2005.11.23.

${ }^{7}$ Анна Герман: с мая Кучма трижды готовил указ об отставке Януковича // Новый регион 2, 2004.12.15.

${ }^{8}$ Премьер-министр Украины Виктор Янукович: «Ющенко уехал в Крым, а я хочу поработать» // Известия, 2006.08.07.

${ }^{9}$ «Оранжевой команде» мешает Тимошенко? // HTB, 18.04.2006. URL: https://www.ntv.ru/novosti/85735/.

${ }^{10}$ Янина Соколовская, Киев. Украинское правительство не приняло приглашение на казнь // Известия, 2013.12.03.

${ }^{11}$ Василий АУТ. С Китаем нам найти общий язык проще, чем с Америкой // Комсомольская правда, 2013.06.18.
} 
Семантическое развитие прилагательного оранжевый связано не только с расширением круга сочетающихся с ним имён существительных, но и с образованием новых синонимических связей с метафорой. В некоторых сочетаниях значение первоначального выражения сохраняется, но оборот приобретает другую коннотацию. Так, в новых выражениях у прилагательного оранжевый появляется сема «крайне опасный»: попытка «оранжевого переворота»; «оранжевые» сценарии у нас не сработают; «оранжевая» технология» в Москве провалилась; персонажами «оранжевых волнений»; «оранжевое движение»; борьбы с «оранжевой угрозой»; «оранжевая чума» (последнее выражение вызывает особенно зловещие ассоциации в связи с угрозой экспорта оранжевой революции в Россию).

Широко используя языковую игру для нестандартного употребления идиом, авторы газетных статей предпочитают трансформировать их компонентный состав или расположение компонентов по отношению друг к другу, что не только не разрушает идиому, а, напротив, интенсифицирует её смысл. Яркие идиоматические комплексы способствуют реализации авторской иронии и повышению экспрессивности высказывания [13, с. 162]: На смену оранжевому цвету «либеральной вольницы» приходит коричневый - цвет разбойной фашизации, цвет оккупации, цвет национального предательства. Здесь русский язык попросту выдавливают из школ. То есть на самом деле именно у оранжевого цвета разрушительных революций хорошо просматривается коричневатый оттенок, а в криках глашатаев слышны отголоски средневековья. Ине заметить это могут только глухие дальтоники. А вернее, люди, старающиеся таковыми казаться1.

Нередко имплицитное выражение авторской иронии создается посредством использования гиперболизации устойчивого выражения и смещения фокуса высказывания в направлении буквального смысла цветового прилагательного: «Оранжевая революция» на Московских прудах: Начало «оранжевой революции» огарей, или красных уток ${ }^{2}$. Авторская ирония в данном контексте выражается имплицитно

Для привлечения внимания потенциальных читателей публицисты используют приём объединения или противопоставления двух или более устойчивых выражений, что приводит к слиянию их фразеологических значений: «Оранжевая революция» 2004 года превратилась в грязную, выцветшую «оранжевую тень»; после падения Сирии, последнего союзника Ирана, попытаются разыграть «оранжевую» карту и там4; Украина сейчас немножко сошла с ума, у неё периодически бывают замутнения вроде «оранжевой» революции, когда шарики за ролики заходят5.

Нередко авторы газетных текстов при помощи антонимического противопоставления двух иносказательных комплексов выражают своё ценностное отношение к чему-либо: «В 2006-м вышел уже немаргинальный фильм о любви на фоне «оранжевой революции» - «Оранжевое небо», в котором были фрагменты с участием Тимошенко и других украинских политиков. О Тимошенко Крутова намерена снять авантюрную политическую драму. Упор будет сделан на личность Тимошенко» ${ }^{6}$.

\footnotetext{
${ }^{1}$ Михаил Шахназаров. Оранжевый для глухих дальтоников // Известия, 2014.03.04.

${ }^{2}$ Василий Вишневский. «Оранжевая революция» на московских прудах // «Наука и жизнь», 2009.

${ }^{3}$ Известия, 2006.08.07.

${ }^{4}$ Евгений АРСЮХИН. Плохо Уолл-Стриту спать? Значит, надо воевать! // Комсомольская правда, 2013.05.03.

${ }^{5}$ Дарья АСЛАМОВА. Почему Молдова рвется в Европу, а гастарбайтеров шлет в Россию. Часть 2 // Комсомольская правда, 2013.11.13.

${ }^{6}$ Мария Амирджанян. В России снимут художественный фильм про Тимошенко // Известия, 2014.04.15.
} 


\section{2. Оранжевый цвет - цвет праздника}

Доминирующим значением устойчивого выражения оранжевое настроение, образованного на основе ассоциативного метафорического переноса, становится значение 'хорошее настроение': Это стиль и подход к жизни, когда вы отказываетесь от отвратительно-серых будней и начинаете жить на яркой стороне [14, с. 459].

В этом значении названию цвета придаётся новая рекламная функция, основанная на создании положительного ассоциативного поля у потенциальных потребителей создаваемого контента, так как упоминание цвета влечёт за собой возникновение определённых положительных ассоциаций (тепло, вкус, настроение) у читателя или слушателя. Именно этим можно объяснить возникновение большого количества названий, включающих в свой состав прилагательное оранжевый: «Оранжевое настроение» - название студийного альбома российской рок-группы Чайф; «Оранжевое настроение» - название детского праздника - День апельсинов; «Оранжевый викинг» - сборник путевых заметок; «Оранжевый гид»- путеводитель по Финляндии; «Оранжевый канал» - дебютный студийный альбом американского исполнителя Фрэнка Оушена; «Оранжевый ЮТУБ» - название группы в социальных сетях; «Оранжевый - хит сезона» - название американского комедийно-драматического сериала; «Оранжевая корова» - название мультсериала; «Оранжевый верблюд» - название магазина игрушек; сеть магазинов коллекционной одежды для детей; «оранжевый кот» - название детского центра; производителя антистрессовых игрушек; «Оранжевая книга сказок» - книга из весенней коллекции Clever «Растем вместе» М. Носова; «Оранжевая компания» / «Оранжевая организация» - название ІТ-компаний, в которых присутствуют элементы гибких проектных групп ${ }^{1 ;}$ “Оранжевая команда»название социальной группы «Одноклассники» в социальных сетях: Дружнее и оранжевее команды Одноклассников нет никого в мире ${ }^{2}$ спортивная команда Голландии; «Оранжевый монстр» второго поколения - название марки дайверских часов.

В перечисленных примерах именно прилагательное оранжевый лежит в основе образования метафорического переноса значения выражения и перехода простого словосочетания в идиоматическое. Подобного рода выражения служат для более экспрессивного описания конкретной ситуации, что делает текст запоминающимся и облегчает понимание авторской позиции: «... если ничем, кроме благих пожеланий, не стимулируется экономический рост - то откуда взойдёт оранжевое солнце процветания? Иуж никак нельзя ждать этого восхода ближайшим утром»3.

Прилагательное оранжевый, помогая создавать яркий образный план устойчивого выражения, не просто способствует выражению экспрессии и повышению эмоциональности высказывания, но и является эффективным средством компрессии информации: «Оранжевые дни» в Сочи: о чём говорит Крамер и от чего бежит Блокхайзен, составив «оранжевой команде» ('спортивная команда, которую так прозвали по наличию оранжевой формы футболистов Голландии') хоть какую-либо конкуренцию;

\footnotetext{
${ }^{1}$ Дмитрий Иванов. Что такое «Оранжевая компания»? // vc.ru [сайт 2021]. URL: https://vc.ru/u/533789-dmitriyivanov/183444-chto-takoe-oranzhevaya-kompaniya.

²В команде оранжевых // Одноклассники.ru [сайт 2021]. URL: https://insideok.ru/blog/v-komande-oranzhevih ${ }^{3}$ РИА Новости, 2005.09.30.
} 
В голландском Апельдорне завершился чемпионат Европы по трековым гонкам, который принёс сборной России «оранжевое настроение». И тут Крамер назвал претендентов на то, чтобы разрушить «оранжевую мечту». Их оказалось не так много - кореец Ли Сын Хун и наш Иван Скобрев. На этом список планирующих вторжение на голландскую территорию у Крамера заканчивается ${ }^{1}$.

В приведённых контекстах устойчивые выражения с прилагательным оранжевый позволяют создать краткую образную характеристику, позволяющую лаконично выразить сложную мысль и дать оценку определённому положению вещей.

\section{3. «Сигнальное» значение прилагательного оранжевый}

Сигнальный цвет - цвет, предназначенный для привлечения внимания людей к непосредственной или возможной опасности, рабочим узлам оборудования, машин, механизмов и (или) элементам конструкции, которые могут являться источниками опасных и (или) вредных факторов, пожарной технике, средствам противопожарной и иной защиты, знакам безопасности и сигнальной разметке. В качестве сигнальных используются яркие, бросающиеся в глаза цвета, и прежде всего оранжевый.

К устойчивым выражениям, включающим «сигнальное» значение прилагательного оранжевый, относятся выражения «оранжевый» уровень опасности - 'второй по уровню опасности после красного'; оранжевая книга - 'основной документ, который устанавливает критерии и правила оценки защищённости компьютерных систем'; 'неофициальное издание нескольких публикаций'; оранжевые жилеты - 'сигнальные жилеты'. На основе метонимического переноса значения у данного выражения появились дополнительные значения: 'гастарбайтеры', 'работники коммунальных служб', 'работники городского транспорта'.

Выражение оранжевая нить, означавшее всегда защиту от злого умысла, приобрело дополнительное значение в контексте всероссийской акции 2021 года, главным атрибутом которой стала оранжевая нить - 'символ объединения и победы над пандемией'.

\section{4. Прилагательное оранжевый в составе сложных цветовых наименований}

Прилагательное оранжевый нередко встречается в составе сложных наименований: жёлто-оранжевая револющия, которая явилась символом духовного пробуждения; оранжево-исламистские революции; оранжево-синий союз; чёрно-оранжевая ленточка -'Георгиевская двухцветная лента'; жёлто-красно-оранжевое солнце. Ср.: Просто содеянного человеком в маленьких городках меньше, чем в мегаполисе, и оно ещё не в состоянии заглушить того разноцветного разнообразия, которое сотворено Богом: зелёная трава, синяя река, жёлто-красно-оранжевое солнце. Но это в тёплое время года. А зимой вся Россия, и большая, и маленькая, - одно сплошное чёрно-серо-белое царство 2 .

\section{Заключение}

В употреблении устойчивых выражений с цветовым прилагательным оранжевый отражается характерная для развития современного русского языка тенденция к экспрессивизации письменного текста, связанная с формированием оценочного высказывания, способного передать отношение журналиста к социальным, культурным,

\footnotetext{
${ }^{1}$ Вероника Гибадиева// Р-Спорт, 2014.02.05.

${ }^{2}$ Дмитрий Соколов-Митрич. Передозировка серая // Известия, 2010.02.16.
} 
политическим событиям. Причём авторы газетных статей предпочитают трансформировать компонентный состав идиом или их расположение по отношению друг к другу, что способствует повышению экспрессивности высказывания. Эволюционирование исходного значения выражений с цветовым прилагательным оранжевый обусловлено изменением отношения в обществе к обозначаемым этими выражениями событиям.

\section{Ссылки / References}

1. Анохина Е.А. Новые фразеологизмы с колоративами чёрный и белый //Лексическая и фразеологическая семантика. М., 2014. С. 131-134.

2. Баринова И. В. Особенности трансформации идиом с обозначением цвета // Вестник МГЛУ. Гуманитарные науки. 2018.Вып. 16 (811). С. 11-19.

3. Бородулина Н. Ю., Макеева М. Н., Будина М. Э. Символы цветных революций в составе их именований // Концепт. 2014. № 08 (август). URL: http://e-koncept.ru/2014/14224.htm (дата обращения: 01.11.2021).

4. Бурунский В. М. Употребительные цветовые прилагательные в современной французской и российской прессе // Изв. Сарат. ун-та. Нов. сер. Сер. Филология. Журналистика. 2016. Т. 16. Вып. 4. С. 388-392.

5. Власова Е. А. Лингвосоциокультурный аспект цветообозначений (на примере цветообозначений белый - white, черный - black, красный - red) // Филологические науки. Вопросы теории и практики. Тамбов: Грамота, 2016. № 5 (59): в 3-х ч. Ч. 1. С. 56-59.

6. Зольникова Ю. В. Цветообозначения во фразеологической картине мира немецкого и русского языков // Вестник Челябинского государственного университета. 2009. № 30 (168). Филология. Искусствоведение. Вып. 35. С. 88-93.

7. Клевцов А. Н. Переносная функция кавычек в современном русском языке

// Рациональное и эмоциональное в художественном тексте: Межвузовский сборник научных трудов. М.: МГОУ, 2009. С. 146-149.

8. Сандакова М. В. Метонимия как основа словообразовательной мотивации (на материале прилагательного) // Вестник Нижегородского университета им. Н. И. Лобачевского. 2015. № 2 (2). C. 541-546.

9. Редькина Н. С. Колоративная лексика в составе фразеологических оборотов. Рязань: РГУ им. С. А. Есенина, 2011.

10. Талапина М. Б. Дискурсивное употребление фразеологических единиц как способ вербиализации индивидуальных картин мира // Вестник Челябинского государственного университета. 2014. № 6 (335). Филология. Искусствоведение. Вып. 88. C. 92-95.

11. Чжан Цзе, Давыдова О. А. Фразеологизмы с колоративным компонентом - особая часть новых фразеологизмов русского языка // Вестник Российского нового университета. Филологические науки. Серия «Человек в современном мире». Выпуск 3. 2018. С. 17-22.

12. Клевцов А. Н. Семантика и функции кавычек в современном русском языке (на материале печатных СМИ): автореф. дис. ... канд. филол. наук. Ярославль: ЯГПУ, 2010. 22 с.

13. Емельянова Н. А. Трансформированные идиомы как продуктивные аксиологические модели в публицистике (на материале английского языка) // Известия РГПУ им. Герцена. 2010. № 126. С. 156-165.

14. Толковый словарь русского языка начала XXI века. Актуальная лексика / Под ред. Г. Н. Скляревской. М.: Эксмо, 2007. 1136 с. 